\title{
Current Trends in Dravet syndrome Research
}

Norimichi Higurashi ${ }^{1,2}$, Taku Uchida ${ }^{2}$, Shinichi Hirose ${ }^{2,3, *}$ and Hideyuki Okano ${ }^{4, *}$

${ }^{1}$ Department of Pediatrics, Jikei University Scool of Medicine, Japan

${ }^{2}$ Central Research Institute for the Pathomechanisms of Epilepsy, Fukuoka University, Japan

${ }^{3}$ Department of Pediatrics, Fukuoka University School of Medicine, Japan

${ }^{4}$ Department of Physiology, Keio University School of Medicine, Japan

\begin{abstract}
Dravet syndrome is devastating infantile-onset epilepsy, often accompanied by severe intellectual disabilities, hyperactive behavior, autistic traits, and ataxia. The discovery in 2001 of theSCN1Amutation as a primary cause of this syndrome has accelerated our understanding of the pathophysiological processes underlying Dravet syndrome. SCN1A encodes the a-subunit of the voltage-gated sodium channel, $\mathrm{Na}_{v} 1.1$. Recent studies using genetically modified mouse models have indicated that haplo insufficiency of $\mathrm{Na}_{\mathrm{v}} 1.1 \mathrm{inGABAergic}$ inhibitory inter neurons in the forebrain may be involved in the seizure susceptibility, fever sensitivity of seizures, premature death, and autistic traits characteristic of Dravet syndrome. More recently, human cellular models of Dravet syndrome have been established using patient-derived induced pluripotent stem cells (iPSCs) from three groups including ours. By taking advantage of these human disease models, functional vulnerabilities in GABAergic neurons have been revealed. Here, we review recent advances in Dravet syndrome research, particularly focusing on the development of iPSC models, and their future directions.
\end{abstract}

Keywords: Epilepsy; $\gamma$-aminobutyric acid; Disease modeling; Genetics; Induced pluripotent stem cells; Mechanism; Mouse model; SCN1A

Abbreviation: DS: Dravet Syndrome; GABA: $\gamma$-amino Butyric Acid; iPSCs: Induced Pluripotent Stem Cells

\section{Introduction}

Dravet syndrome (DS)is a devastating epilepsy syndrome, which was first described by Dr. Charlotte Dravet in 1978 [1]. Generalized or unilateral clonic seizures appear in previously healthy infants, and are frequently associated with fever [2]. These seizures tend to evolve into status epilepticus and occur frequently especially during the early phases of DS. Other seizures, including focal, absence, and myoclonic seizures appear later. Seizures are refractory to most currently available treatments, and severe intellectual disabilities develop after seizure onset, often accompanied by hyperactive behavior and autistictraits. Ataxia worsens with age, resulting in significant gait disturbance. Furthermore, $10-20 \%$ of the afflicted children experience premature death $[3,4]$. Thus, the development of new treatment is urgently needed.

Mutations in the SCN1A gene in patients with DS were first reported in 2001[5]. Subsequent studies supported the hypothesis that the SCN1A defect is the primary cause of DS [6,7]; these findings have triggered a number of studies attempting to uncover the pathogenic mechanisms underlying DS. These studies have employed electrophysiological functional analysis of forcedly expressed $\mathrm{Na}_{\mathrm{v}} 1.1$ mutants [8,9], mouse models based on heterozygotes of an SCN1A knock-out/knock-in mouse [10,11], and more recently, human cellular models using patient-derived induced pluripotent stem cells (iPSCs) [12-14]. First, we briefly review previous research on DS and then describe our recent research on generating an iPSC model for DS.

\section{Genetic alteration in $S C N 1 A$}

SCN1A encodes the $\alpha$-subunit of the voltage-gated sodium channel $\mathrm{Na}_{\mathrm{v}} 1.1$ (Figure 1) [15]. Abnormalities in the SCN1A gene were first reported in patients with genetic epilepsy febrile seizures plus (GEFS+) [15], and have been also identified in patients with other clinical phenotypes, including cryptogenic focal/generalized epilepsies [16].
However, DS is the primary phenotype in which arobust correlation with SCN1A defects has been confirmed [17,18]: $70-80 \%$ of patients with DS carry SCN1A abnormalities [19,20].

Nearly 700 mutations in theSCN1Agene that are associated with DS have so far been identified [21], and most of them are de novo. These mutations include nonsense, missense, splice site, and frameshift mutations, and are distributed throughout the gene. Specific genotypephenotype correlations remain unclear, but truncation mutations, harbored by half of the patients with DS, appear to be associated with a more severe phenotype than missense mutations [22]. Exonic or micro chromosomal deletions involving SCN1Aor its promoter region have also been identified in patients with DS [23-27]. Other genes potentially associated with DS or similar phenotypes include SCN1B [28], SCN2A [29], GABRG2 [30], and PCDH19 [31,32]. However, mutations in the former three occur rarely, andonly a minority ofpatients with $\mathrm{PCDH} 19$ mutations present with the DS phenotype [33,34].

\section{Functional alterations of mutated $\mathrm{Na}_{\mathrm{v}} 1.1$}

Electrophysiological studies examining the functions of mutated $\mathrm{Na}_{\mathrm{v}} 1.1$ channels expressed in HEK293or tsA-201 cells have revealed that many of the DS-associated missense mutations result in an on functional sodium channel $[8,9,35,36]$, and this loss-of-function of the channel may be associated with DS. One study revealed that expressed

*Corresponding authors: Shinichi Hirose, Department of Pediatrics, Fukuoka University, Jonan-ku Fukuoka, 814-0180 Japan, Tel: +81-92-801-1011; Fax: +8192-863-1970; E-mail: hirose@fukuoka-u.ac.jp

Hideyuki Okano, Department of Physiology, Keio University, School of Medicine 35 Shinanomachi, Shinjuku-ku, Tokyo, 160-8582, Japan, Tel: +81-3-5363-3747; Fax: +81-3-3357-5445; E-mail: hidokano@a2.keio.jp

Received May 23, 2013; Accepted July 17, 2013; Published July 25, 2013

Citation: Higurashi N, Uchida T, Hirose S, Okano H (2013) Current Trends in Dravet syndrome Research. J Neurol Neurophysiol 4: 152. doi:10.4172/21559562.1000152

Copyright: (c) 2013 Higurashi N, et al. This is an open-access article distributed under the terms of the Creative Commons Attribution License, which permits unrestricted use, distribution, and reproduction in any medium, provided the original author and source are credited. 


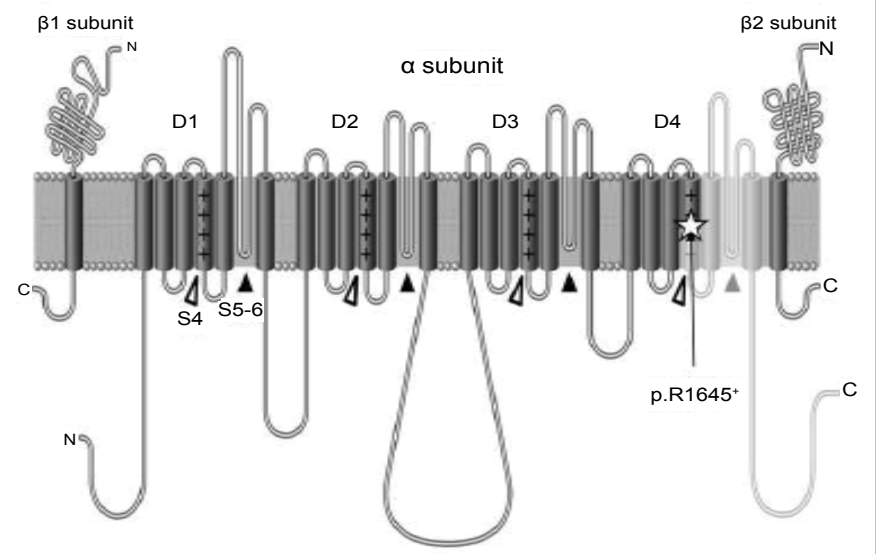

Figure 1: $\mathrm{Na}_{\mathrm{v}} 1.1$ architecture and the location of the patient's mutation. $\mathrm{Na}_{\mathrm{v}} 1.1$ consists of one main pore-forming $\alpha$-subunit and two auxiliary $\beta$-subunits. The $\alpha$-subunit comprises four homologous domains (D1-D4), each with six transmembrane regions (S1-S6). The channel pore is formed by the assembly of four linker regions between the S5 and S6 segments (solid arrowheads). Voltage sensitivity is mediated by positively charged residues in the S4 regions (open arrowheads) that move outward when depolarized to open the channel. The nonsense mutation of the patient was located in D4/S4 (white star), which terminated at the R1645 residue, and the $\mathrm{Na}_{\mathrm{v}} 1.1$ protein looses the faded protein of the portion.

truncated human $\mathrm{Na}_{\mathrm{v}} 1.1\left(\mathrm{hNa}_{\mathrm{v}} 1.1\right)$ did not affect the channel function of co-expressed wild-type human $\mathrm{hNa}_{\mathrm{v}} 1.1, \mathrm{hNa}_{\mathrm{v}} 1.2, \mathrm{hNa}_{\mathrm{v}} 1.3$, or $\mathrm{hNa}_{\mathrm{v}} 1.6$ [37]. It is also true that $S C N 1 A$ abnormalities in DS frequently include truncation mutations (mainly nonsense mutations) and gene deletions, while there is little evidence showing that the truncated $\mathrm{hNa}_{\mathrm{v}} 1.1$ protein is expressed associated with nonsense mutation. Nonsense mutations of SCN1A gene could result in nonsense-mediated mRNA decay. Collectively, it is tempting to speculate that haplo insufficiency may be an underlying mechanism of DS. However, some missense mutations were found to induce gain-of-function of $\mathrm{Na}_{\mathrm{v}} 1.1$ by way of activating sodium currents because of impairments in fast inactivation mechanisms [9]. It seems likely that the functional basis of SCN1A abnormalities related to DS may be more complex.

\section{Dysfunction of GABAergic Interneurons in Mouse DS Models}

Yu et al. first reported a mouse DS model based on Scn1a knockout in 2006 [10], which exhibited spontaneous seizures, temperaturedependent seizure susceptibility [38], and ataxia [39]. They examined $\mathrm{Na}_{\mathrm{v}} 1.1$ expression in the hippocampal GABAergic interneurons, and found a reduced sodium current density and impaired action potential generation in those neurons of $S c n 1 a^{-/-}$and $S c n 1 a^{+-}$mice compared to wild-type mice, while these were normal in the pyramidal neurons. Reduced sodium current density was also confirmed in the Purkinje neurons of these animals [39]: this reduced current density may be involved in the ataxia associated with DS. Ogiwara et al. identified a parvalbumin-positive subgroup of GABAergic interneurons, which directly regulates the excitation of pyramidal neurons, as the primary type of $\mathrm{Na}_{\mathrm{v}} 1.1$-expressing neurons in the neocortex and hippocampus [11]; moreover, intense $\mathrm{Na}_{\mathrm{v}} 1.1$ expression was identified in their axon initial segments. The researchers generated Scn1a knock-in mice with the R1407* mutation, which exhibited spontaneous seizures, autistic traits, and cognitive decline [40], and impaired action potential generation in their neocortical GABAergic interneurons. These heterozygous knock-out/knock-in mice were also prone to premature death $[10,11]$.

Conditional SCN1Aknock-out, which was achieved by the Cre-mediated heterozygous deletion of floxed exonic regions, helped elucidate the brain region responsible for some of the major clinical features of DS [41]. Specifically, Dlx1/2-enhancer-driven CredeletedScn $1 a$ in the mouse forebrain GABAergic interneurons [42] These mice exhibited spontaneous seizures, temperature-dependent seizure susceptibility, premature death, and autistic traits[43], as was observed in mice with global SCN1A deletion. Kalume, et al. made an extremely interesting observation regarding the mechanisms of sudden unexpected death during tonic-clonic seizures [44]: the mice that died had increased seizure frequency and ictal bradycardia, which could be ameliorated by atropine, suggesting that an increase in parasympathetic activity occurs. SCN1A knock-out in the heart did not affect heart rate.

In the global knock-in and the conditional knock-out mice, administration of drugs that act to enhance GABAergic transmission, such as clonazepam, clobazam, or stiripentol ameliorated the seizures and behavioral impairments $[43,45,46]$, supporting the notion that dysfunction of GABAergic interneurons is involved in the symptoms described above.

\section{Human-Based Cellular Models for DS Developed Using Patient-Derived iPSCs}

\section{Generation of DS patient-derived iPSCs}

Because it remains unclear whether mouse models faithfully reproduce the pathology occurring in the patient's brain, it is desirable to study patient's neurons directly. After the development of human iPSCs by Yamanaka et al. in 2007 [47], many neurological diseases have been modeled using patient-derived iPSCs [48-53], and pathogenic alterations have been identified in their differentiated neurons. Until recently, however, no such effort has been reported for epilepsy.

We recently generated two lines of iPSCs (D1-1 and D1-6) from a female patient with a core DS phenotype, who harbors a nonsense mutation in SCN1A (p.R1645*, Figure1) [12]. Reprogramming factors (Sox2, Klf4, Oct3/4, and $c-M y c$ ) were retrovirally transduced into the skin fibroblasts, which were biopsied from her upper arm at the age of 29 years. The generated iPSCs displayed undifferentiated status and pluripotency, harbored the patient's mutation in their SCN1A gene, and could be efficiently and reliably differentiated into neuronal cells. Neuronal differentiation from the iPSCs was performed using a method established by Okada et al. [54] with a slight modification, in which a month of embryoid body formation is followed by 3-5 weeks of neurosphere formation. Terminal differentiation into mature neurons was achieved by adherent culture of dissociated or undissociated neurosphere cells. For control experiments, we used 201B7, an iPSC line that was developed from a healthy female [47].

\section{Functional Vulnerabilities in Patient iPSCs-Derived GABAergic Neurons}

Because iPSCs-derived neurons obtained by the method described above are highly heterogeneous with regard to their neuronal subtypes and maturities, it is critical to analyze only one specific type of neuronat a defined level of maturity in order to determine whether the neurons are actually pathologic. As a first step to overcoming these difficulties, we generated a lentiviral reporter for SCN1A expression for electrophysiological assays; this harbors one main SCN1A promoter sequence [26], followed by a5'-untranslated exon 
Citation: Higurashi N, Uchida T, Hirose S, Okano H (2013) Current Trends in Dravet syndrome Research. J Neurol Neurophysiol 4: 152. doi:10.4172/2155-9562.1000152

(to enhance expression specificity) [55], and Venus cDNA (Figure 2): $80-90 \%$ of the reporter Venus-positive neurons were $\mathrm{Na}_{\mathrm{v}} 1.1$ positive. Moreover, immunocytochemistry revealed that $>50 \%$ of $\mathrm{Na}_{\mathrm{v}} 1.1$ positive neurons, and $>70 \%$ of the reporter Venus-positive neurons were GABAergic (GAD67 (GABAergic neuron marker) and GABApositive, respectively). VGlut1-positive (glutamatergic neuron marker) neurons appeared only rarely, and we could not evaluate their $\mathrm{Na}_{\mathrm{v}} 1.1$ expression and functional properties sufficiently. These findings indicate that the reporter detects $\mathrm{Na}_{\mathrm{v}} 1.1$-positive GABAergic neurons with a high homogeneity.

Neuronal maturity is also critical for accurate functional assessment. For this purpose, we sought to improve the conditions for neuron selection in electrophysiological assays, and finally set the following requirements: $3-7$ weeks (average, $30-45$ days) of terminal differentiation period; clear reporter fluorescence; mature morphology (large cell body size and growth of $\geq 4$ neurites); larger capacitance ( $\geq 30$ $\mathrm{pF})$; and more negative resting membrane potential $(\leq-30 \mathrm{mV})$. Using the current-clamp technique, the number and the amplitude of action potentials triggered by $500-\mathrm{ms}$ depolarizing current injections were evaluated at various current intensities (input-output relationship). In the final analyses, functionally immature neurons, which generated $<10$ action potentials during the stimulation protocol, were further omitted.

Although the capacitances, resting membrane potentials, firing thresholds, and peak voltages of action potentials were identical among the different cell lines, input-output relationships differed when the injection currents intensified; there was a marked attenuation of both the amplitude and the number of evoked action potentials in patient's neurons compared to control neurons (Figure 3). These findings may indicate a reduced output capacity of the patient-derived neurons,
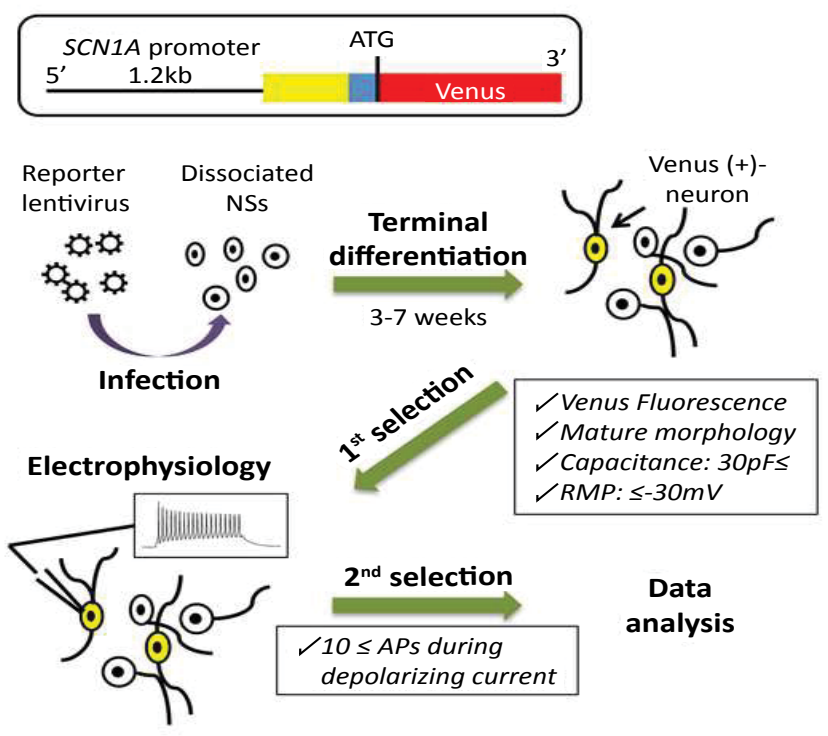

Figure 2: Diagram of the $S C N 1 A$ reporter and neuron selection strategy for electrophysiological analyses: In the construct diagram, the yellow portion indicates the 5 -untranslated exonic sequence, and light blue indicates the $5^{\prime}$-untranslated sequence of the first coding exon. This construct was transduced into the dissociated neurospheres by using lentiviral vectors. After 3-7 weeks of terminal differentiation, putatively mature neurons that satisfied several requirements (see main text) were selected for electrophysiological analysis. Functionally immature neurons with in adequate action potential generation were excluded from analysis. APs, action potentials; RMP, resting membrane potential.

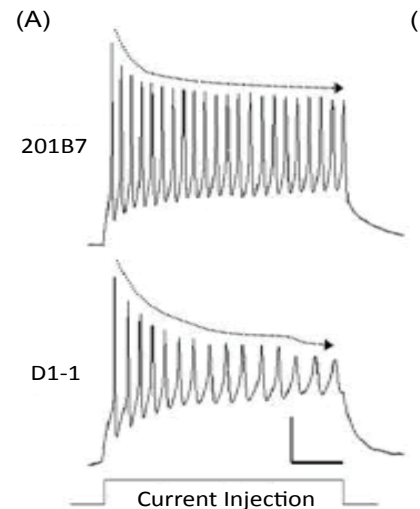

(B)

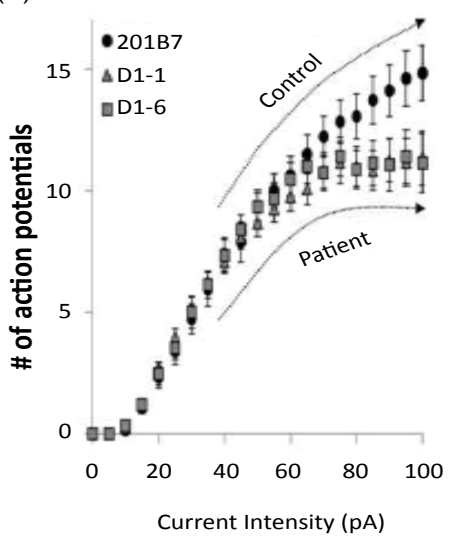

Figure 3: Representative traces of action potential trains and input-output relationships: (adapted from Reference [12] with modifications). (A) The 500ms current injection period is indicated below. The traces presented are those evoked by a 100-pA current injection. Toward the end of the current injection, D1-1 neurons showed more prominent attenuation of action potential amplitude compared to 201B7 neurons, as indicated by the dotted arrows. The frequency of action potentials was also lower in D1-1. Scale bars indicate $20 \mathrm{mV}$ and $100 \mathrm{~ms}$. (B)Mean of the total number of action potentials evoked during the 500-ms stimulation period vs. injection current intensity (input-out put relationship). In all cell lines, the number of action potentials increased with intensifying currents. However, when current intensities exceeded $60 \mathrm{pA}$, the rate of action potential increase plateaued in both patient lines, which was not the case in control cells.

particularly in the GABAergic subgroup, and are reminiscent of findings from murine DS models $[10,11]$.

\section{Hyperexcitability in DS iPSCs-Derived Neurons}

Liu et al. also generated iPSCs from two patients with DS and differentiated the cells into neurons by alternate methods [13]. The neurons were divided into two groups according to their morphologybipolar or pyramidal-and their electrophysiological properties were evaluated. In both groups of neurons, the patients-derived lines showed lower firing thresholds, higher sodium current densities, and a higher rate of spontaneously bursting neurons than cell lines derived from controls, suggesting hyperexcitability of DS neurons. Most recently, Jiao et al. also confirmed the hyperexcitability in excitatory neurons derived from DS patient-iPSCs [14]. Although such findings on the hyper excitability were not confirmed in our preliminary experiments (Higurashi et al., unpublished results), they provided a novel gainof-function hypothesis for the mechanisms underlying seizure susceptibility in DS, which have not been revealed by murine research. Further development of the iPSC research technique will be necessary to elucidate the precise mechanisms involved.

\section{Future Directions of DS Research Using Patient- Derived iPSCs}

Disease modeling with patient-derived iPSCs has just begun, particularly in the field of epilepsy. Although the results of these two iPSC studies on DS are not immediately beneficial for patient treatment, they strongly indicate the utility of the new platform for human epilepsy research. In the next step, refinement of the culture technique and a more cell-type-specific analysis for various types of neurons (e.g. glutamatergic, parvalbumin-positive GABAergic, calretinin-positive GABAergic, and somatostatin-positive GABAergic, etc) will be necessary. The continued use of mouse models to confirm our findings 
Citation: Higurashi N, Uchida T, Hirose S, Okano H (2013) Current Trends in Dravet syndrome Research. J Neurol Neurophysiol 4: 152. doi:10.4172/2155-9562.1000152

from iPSCs will facilitate the elucidation of key pathophysiological mechanisms and critical therapeutic targets in human patients with DS.

\section{Acknowledgements}

Original investigation described in the present review article was supported by the Project for the Realization of Regenerative Medicine from the Japanese Ministry of Education, Culture, Sports, Science and Technology (MEXT) to H.O.; The Program for Intractable Disease Research utilizing Disease-specific iPS Cells from Japan Science and Technology Agency (JST) to H.O.;a Grant-in-Aids for Scientific Research (A) (21249062), for Challenging Exploratory Research (23659529), and for Bilateral Joint Research Projects from Japan Society for the Promotion of Science (JSPS) to S.H.; the Adaptable and Seamless Technology Transfer Program through Target-driven R\&D (A-STEP) Exploratory Research from JST to S.H.; Research Grants for Nervous and Mental Disorder (21B-5), Health and Labor Science Research Grant (21210301 and KB220001), and a Grant-in-aid for the Research on Measures for Intractable Diseases (No. H22 Nanji-Ippan-49) from the Ministry of Health, Labor and Welfare (MHLW) to S.H.; Research grants from The Japan Foundation for Pediatric Research (10-003), The Clinical Research Promotion Foundation, and Kaibara Morikazu Medical Science Promotion Foundation to N.H.; and the 2013-2017 "Central Research Institute for the Molecular Pathomechanisms of Epilepsy of Fukuoka University" Recommended Projects of Fukuoka University (117016) to S.H.

\section{References}

1. Fujiwara $T$ (2006) Clinical spectrum of mutations in SCN1A gene: severe myoclonic epilepsy in infancy and related epilepsies. Epilepsy Res 70 Supp 1: S223-230.

2. Dravet C, Bureau M, Oguni H, Fukuyama Y, Cokar O (2005) Severe myoclonic epilepsy in infancy (Dravet syndrome): Epileptic syndromes in infancy, childhood and adolescence. (4thedn), John Libbey Eurotext, Montrouge.

3. Sakauchi M, Oguni H, Kato I, Osawa M, Hirose S, et al. (2011) Retrospective multiinstitutional study of the prevalence of early death in Dravet syndrome. Epilepsia 52: 1144-1149.

4. Genton P, Velizarova R, Dravet C (2011) Dravet syndrome: the long-term outcome. Epilepsia 52 Suppl 2: 44-49.

5. Claes L, Del-Favero J, Ceulemans B, Lagae L, Van Broeckhoven C, et al. (2001) De novo mutations in the sodium-channel gene SCN1A cause severe myoclonic epilepsy of infancy. Am J Hum Genet 68: 1327-1332.

6. Fukuma G, Oguni H, Shirasaka Y, Watanabe K, Miyajima T, et al. (2004) Mutations of neuronal voltage-gated $\mathrm{Na}+$ channel alpha 1 subunit gene SCN1A in core severe myoclonic epilepsy in infancy (SMEI) and in borderline SMEI (SMEB). Epilepsia 45: 140-148.

7. Depienne C, Trouillard O, Saint-Martin C, Gourfinkel-An I, Bouteiller D, et al. (2009) Spectrum of SCN1A gene mutations associated with Dravet syndrome: analysis of 333 patients. J Med Genet 46: 183-191.

8. Lossin C, Rhodes TH, Desai RR, Vanoye CG, Wang D, et al. (2003) Epilepsyassociated dysfunction in the voltage-gated neuronal sodium channel SCN1A. J Neurosci 23: 11289-11295.

9. Rhodes TH, Lossin C, Vanoye CG, Wang DW, George AL Jr (2004) Noninactivating voltage-gated sodium channels in severe myoclonic epilepsy of infancy. Proc Natl Acad Sci U S A 101: 11147-11152.

10. Yu FH, Mantegazza M, Westenbroek RE, Robbins CA, Kalume F, et al. (2006) Reduced sodium current in GABAergic interneurons in a mouse model of severe myoclonic epilepsy in infancy. Nat Neurosci 9: 1142-1149.

11. Ogiwara I, Miyamoto H, Morita N, Atapour N, Mazaki E, et al. (2007) Nav1.1 localizes to axons of parvalbumin-positive inhibitory interneurons: a circuit basis for epileptic seizures in mice carrying an Scn1a gene mutation. J Neurosci 27: 5903-5914.

12. Higurashi N, Uchida T, Lossin C, Misumi Y, Okada Y, et al. (2013) A human Dravet syndrome model from patient induced pluripotent stem cells. Mol Brain 6: 19.

13. Liu Y, Lopez-Santiago LF, Yuan Y, Jones JM, Zhang H, et al. (2013) Dravet syndrome patient-derived neurons suggest a novel epilepsy mechanism. Ann Neurol .

14. Jiao J, Yang Y, Shi Y, Chen J, Gao R, et al. (2013) Modeling Dravet syndrome using induced pluripotent stem cells (iPSCs) and directly converted neurons. Hum Mol Genet

15. Escayg A, MacDonald BT, Meisler MH, Baulac S, Huberfeld G, et al. (2000)
Mutations of SCN1A, encoding a neuronal sodium channel, in two families with GEFS+2. Nat Genet 24: 343-345.

16. Harkin LA, McMahon JM, lona X, Dibbens L, Pelekanos JT, et al. (2007) The spectrum of SCN1A-related infantile epileptic encephalopathies. Brain 130 843-852.

17. Lossin C (2009) A catalog of SCN1A variants. Brain Dev 31: 114-130.

18. Hirose S, Scheffer IE, Marini C, De Jonghe P, Andermann E, et al. (2013) SCN1A testing for epilepsy: application in clinical practice. Epilepsia 54: 946952.

19. Marini C, Scheffer IE, Nabbout R, Suls A, De Jonghe P, et al. (2011) The genetics of Dravet syndrome. Epilepsia 52 Suppl 2: 24-29.

20. Wang JW, Shi XY, Kurahashi H, Hwang SK, Ishii A, et al. (2012) Prevalence of SCN1A mutations in children with suspected Dravet syndrome and intractable childhood epilepsy. Epilepsy Res 102: 195-200.

21. Meisler MH, O'Brien JE, Sharkey LM (2010) Sodium channel gene family: epilepsy mutations, gene interactions and modifier effects. J Physiol 588: 1841 1848.

22. Marini C, Mei D, Temudo T, Ferrari AR, Buti D, et al. (2007) Idiopathic epilepsies with seizures precipitated by fever and SCN1A abnormalities. Epilepsia 48 1678-1685.

23. Madia F, Striano P, Gennaro E, Malacarne M, Paravidino R, et al. (2006) Cryptic chromosome deletions involving SCN1A in severe myoclonic epilepsy of infancy. Neurology 67: 1230-1235.

24. Suls A, Claeys KG, Goossens D, Harding B, Van Luijk R, et al. (2006) Microdeletions involving the SCN1A gene may be common in SCN1A-mutationnegative SMEI patients. Hum Mutat 27: 914-920.

25. Wang JW, Kurahashi H, Ishii A, Kojima T, Ohfu M, et al. (2008) Microchromosomal deletions involving SCN1A and adjacent genes in severe myoclonic epilepsy in infancy. Epilepsia 49: 1528-1534.

26. Nakayama T, Ogiwara I, Ito K, Kaneda M, Mazaki E, et al. (2010) Deletions of SCN1A 5' genomic region with promoter activity in Dravet syndrome. Hum Mutat 31: 820-829.

27. Shi X, Wang J, Kurahashi H, Ishii A, Higurashi N, et al. (2012) On the likelihood of SCN1A microdeletions or duplications in Dravet syndrome with missense mutation. Brain Dev 34: 617-619.

28. Patino GA, Claes LR, Lopez-Santiago LF, Slat EA, Dondeti RS, et al. (2009) A functional null mutation of SCN1B in a patient with Dravet syndrome. Neurosci 29: 10764-10778.

29. Shi X, Yasumoto S, Nakagawa E, Fukasawa T, Uchiya S, et al. (2009) Missense mutation of the sodium channel gene SCN2A causes Dravet syndrome. Brain Dev 31: 758-762.

30. Harkin LA, Bowser DN, Dibbens LM, Singh R, Phillips F, et al. (2002) Truncation of the $\operatorname{GABA}(\mathrm{A})$-receptor gamma2 subunit in a family with generalized epilepsy with febrile seizures plus. Am J Hum Genet 70: 530-536.

31. Depienne C, Bouteiller D, Keren B, Cheuret E, Poirier K, et al. (2009) Sporadic infantile epileptic encephalopathy caused by mutations in $\mathrm{PCDH} 19$ resembles Dravet syndrome but mainly affects females. PLoS Genet 5: e1000381.

32. Marini C, Mei D, Parmeggiani L, Norci V, Calado E, et al. (2010) Protocadherin 19 mutations in girls with infantile-onset epilepsy. Neurology 75: 646-653.

33. Higurashi N, Shi X, Yasumoto S, Oguni H, Sakauchi M, et al. (2012) PCDH19 mutation in Japanese females with epilepsy. Epilepsy Res 99: 28-37.

34. Higurashi N, Nakamura M, Sugai M, Ohfu M, Sakauchi M, et al. (2013) PCDH19-related female-limited epilepsy: Further details regarding early clinical features and therapeutic efficacy. Epilepsy Res

35. Ohmori I, Kahlig KM, Rhodes TH, Wang DW, George AL Jr (2006) Nonfunctional SCN1A is common in severe myoclonic epilepsy of infancy. Epilepsia 47: 16361642.

36. Sugawara T, Tsurubuchi Y, Fujiwara T, Mazaki-Miyazaki E, Nagata K, et al. (2003) Nav1.1 channels with mutations of severe myoclonic epilepsy in infancy display attenuated currents. Epilepsy Res 54: 201-207.

37. Bechi G, Scalmani P, Schiavon E, Rusconi R, Franceschetti S, et al. (2012) Pure haploinsufficiency for Dravet syndrome $\mathrm{Na}(\mathrm{V}) 1.1$ (SCN1A) sodium channel truncating mutations. Epilepsia 53: 87-100. 
Citation: Higurashi N, Uchida T, Hirose S, Okano H (2013) Current Trends in Dravet syndrome Research. J Neurol Neurophysiol 4: 152. doi:10.4172/2155-9562.1000152

Page 5 of 5

38. Oakley JC, Kalume F, Yu FH, Scheuer T, Catterall WA (2009) Temperatureand age-dependent seizures in a mouse model of severe myoclonic epilepsy in infancy. Proc Natl Acad Sci U S A 106: 3994-3999.

39. Kalume F, Yu FH, Westenbroek RE, Scheuer T, Catterall WA (2007) Reduced sodium current in Purkinje neurons from Nav1.1 mutant mice: implications for ataxia in severe myoclonic epilepsy in infancy. J Neurosci 27: 11065-11074.

40. Ito S, Ogiwara I, Yamada K, Miyamoto H, Hensch TK, et al. (2012) Mouse with $\mathrm{Na}(\mathrm{v}) 1.1$ haploinsufficiency, a model for Dravet syndrome, exhibits lowered sociability and learning impairment. Neurobiol Dis 49C: $29-40$.

41. Cheah CS, Yu FH, Westenbroek RE, Kalume FK, Oakley JC, et al. (2012) Specific deletion of NaV1.1 sodium channels in inhibitory interneurons causes seizures and premature death in a mouse model of Dravet syndrome. Proc Nat Acad Sci U S A 109: 14646-14651.

42. Long JE, Swan C, Liang WS, Cobos I, Potter GB, et al. (2009) DIx1\&2 and Mash1 transcription factors control striatal patterning and differentiation through parallel and overlapping pathways. J Comp Neurol 512: 556-572.

43. Han S, Tai C, Westenbroek RE, Yu FH, Cheah CS, et al. (2012) Autisticlike behaviour in Scn1a+/- mice and rescue by enhanced GABA-mediated neurotransmission. Nature 489: 385-390.

44. Kalume F, Westenbroek RE, Cheah CS, Yu FH, Oakley JC, et al. (2013) Sudden unexpected death in a mouse model of Dravet syndrome. J Clin Invest 123: $1798-1808$

45. Cao D, Ohtani H, Ogiwara I, Ohtani S, Takahashi Y, et al. (2012) Efficacy of stiripentol in hyperthermia-induced seizures in a mouse model of Dravet syndrome. Epilepsia 53: 1140-1145.

46. Oakley JC, Cho AR, Cheah CS, Scheuer T, Catterall WA (2013) Synergistic GABA-enhancing therapy against seizures in a mouse model of Drave syndrome. J Pharmacol Exp Ther 345: 215-224.

47. Takahashi K, Tanabe K, Ohnuki M, Narita M, Ichisaka T, et al. (2007) Induction of pluripotent stem cells from adult human fibroblasts by defined factors. Cell 131: $861-872$

48. Soldner F, Hockemeyer D, Beard C, Gao Q, Bell GW, et al. (2009) Parkinson's disease patient-derived induced pluripotent stem cells free of vira reprogramming factors. Cell 136: 964-977.

49. Marchetto MC, Carromeu C, Acab A, Yu D, Yeo GW, et al. (2010) A mode for neural development and treatment of Rett syndrome using human induced pluripotent stem cells. Cell 143: 527-539.

50. Brennand KJ, Simone A, Jou J, Gelboin-Burkhart C, Tran N, et al. (2011) Modelling schizophrenia using human induced pluripotent stem cells. Nature 473: $221-225$

51. Yagi T, Ito D, Okada Y, Akamatsu W, Nihei Y, et al. (2012) Modeling familia Alzheimer's disease with induced pluripotent stem cells. Rinsho Shinkeigaku 52:1134-1136.

52. Imaizumi $Y$, Okada $Y$, Akamatsu W, Koike M, Kuzumaki N, et al. (2012) Mitochondrial dysfunction associated with increased oxidative stress and $\hat{I} \pm$ synuclein accumulation in PARK2 iPSC-derived neurons and postmortem brain tissue. Mol Brain 5: 35

53. Nihei $Y$, Ito D, Okada Y, Akamatsu W, Yagi T, et al. (2013) Enhanced aggregation of androgen receptor in induced pluripotent stem cell-derived neurons from spinal and bulbar muscular atrophy. J Biol Chem 288: 8043-8052.

54. Okada Y, Matsumoto A, Shimazaki T, Enoki R, Koizumi A, et al. (2008) Spatiotemporal recapitulation of central nervous system development by murine embryonic stem cell-derived neural stem/progenitor cells. Stem Cells 26: 3086-3098.

55. Long YS, Zhao QH, Su T, Cai YL, Zeng Y, et al. (2008) Identification of the promoter region and the 5 -untranslated exons of the human voltage-gated sodium channel Nav1.1 gene (SCN1A) and enhancement of gene expression by the 5'-untranslated exons. J Neurosci Res 86: 3375-3381. 